\title{
A irrupção do político: resposta da psicanálise e o laço social
}

\section{The irruption of politics: the response of psychoanalysis and the social bond}

\author{
Albert Nguyên ${ }^{*}$ \\ Tradução de Vera Pollo ${ }^{* *}$
}

\begin{abstract}
Resumo
Partindo da constatação de que o discurso de Lacan sobre o lugar da psicanálise no político não poderia ser o mesmo depois da crise financeira de 2008, que atingiu a Europa e a América Latina, o autor propõe-se a responder, lançando mão dos últimos seminários de Lacan, o que se passou de fato na transformação do discurso do mestre, DM, em discurso do capitalismo, também chamado de "discurso do mestre pervertido". Após verificar a frequência de casos "especiais" - isto é, de difícil diagnóstico - na clínica psicanalítica contemporânea, e a invasão desta mesma clínica pela questão da identidade, a questão inicial desdobra-se em: Como tratar o sintoma que vem do real? Como fazer laço social na falência do desejo e na proliferação dos gozos? A resposta encontra-se no consentimento à singularidade, o que somente a prática psicanalítica permite. Por esse motivo, a psicanálise não está ultrapassada nem esvaziada, pelo contrário, cresce diariamente.

Palavras-chave: DISCURSO DO MESTRE; DISCURSO DO CAPITALISMO; SINTOMA; GOZO; SINGULARIDADE.
\end{abstract}

\begin{abstract}
Starting from the observation that Lacan's discourse about the place of psychoanalysis in politics could not be the same after the 2008 financial crisis that hit Europe and Latin America, the author proposes to respond, making use of Lacan's last seminars, to what actually happened in the transformation of the master's discourse, MD, into a discourse of capitalism, also called the "perverted master's discourse". After confirming the frequency of "special" cases - that is, difficult to diagnose - in the contemporary psychoanalytic clinic, and the encroachment of the issue of identity into that clinic, the initial issue unfolds as: How to treat the symptom that comes from the real? How to make a social link given the failure of desire and the proliferation of pleasures? The answer may be found in consenting to uniqueness, which only psychoanalytic practice can allow. For this reason, psychoanalysis is not outdated or empty, on the contrary, it grows on a daily basis.
\end{abstract}

Keywords: MASTER'S DISCOURSE; DISCOURSE OF CAPITALISM; SYMPTOM; ENJOYMENT;UNIQUENESS.

\footnotetext{
* Psicanalista. Membro fundador da Internacional dos Fóruns. AME da Escola de Psicanálise dos Fóruns do Campo Lacaniano (IF-EPFCL) 118. Autor regular da Revista l'En-je lacanien. Endereço: Rue d' Assas, 75006. Paris. E-mail: a.nguyen33@numericable.fr

** Tradução de Vera Pollo. Psicanalista. Professora dos Programas de Pós-graduação em Psicanálise, Saúde Sociedade da Universidade Veiga de Almeida (RJ).

Endereço: Rua Ibituruna, 108 casa III. Rio de Janeiro.

E-mail: verapollo8@gmail.com
} 
Lacan colocou a questão do lugar da psicanálise no âmbito político desde 1968. Acredito, por isso, que, no atual momento, seu discurso não seria mais o mesmo. Em 2008, a crise econômica não atingiu apenas a Europa, mas também a América do Sul. Uma crise econômica e financeira sempre se faz acompanhar de diferentes respostas sociais que devem ser levadas em consideração: crescimento dos nacionalismos e fundamentalismos, terrorismo e fluxo migratório, crescimento da precariedade e das segregações, racismo e antissemitismo aos quais se acrescenta ainda o uso de drogas, sem contar as práticas sexuais desenfreadas e o impacto das redes sociais.

Por outro lado, no momento em que o capitalismo neoliberal e a ciência nos oferecem um "mundo novo", vemos nascerem os grandes movimentos populares que estremecem o sistema e que o interrogam, além ou aquém de sua manifestação, chegando a propor soluções alternativas ou, pelo menos, a pensar nelas, e até com algum sucesso. Com efeito, as recentes eleições espanholas foram marcadas pela vitória do Podemos, depois de Syriza, na Grécia, e da eleição de Manuela Carmena, a "indignada", como prefeita de Madri, e de Ada Colau em Barcelona. Aliás, não se pode deixar de mencionar a enorme mobilização popular na França após o atentado à revista Charlie Hebdo, as manifestações no Brasil contra a corrupção e a pobreza, e na Argentina, contra a política feminicida. É preciso destacar que, diante desse esboço de movimentos populares, perfila-se o espectro inquietante de Daesh, retorno da religião mais radical e mais ameaçadora, frente à qual se mostram bem hesitantes e bem impotentes os políticos de diferentes regiões.

Desde 1968, a análise que Lacan fez dos conflitos sociais, em diferentes ocasiões e indo além do que Freud propusera em seu Totem e tabu, levara-o a profetizar o aumento do racismo e da segregação, nosso futuro de mercados comuns, a fraternidade fundada na segregação e a indecência de slogans do tipo "Liberdade - igualdade - fraternidade" face aos malefícios dos sistemas ideológicos totalitários, e democráticos.

No ano de 1972, em Milão, Lacan propôs algumas balizas para o discurso capitalista que ainda permanecem verdadeiras: o discurso capitalista foi acrescentado por Lacan aos discursos do Mestre, da Universidade, da histérica e do analista. Podemos pensar que esse acréscimo não é anódino e é verdade que o mestre antigo de Platão está ultrapassado nos dias atuais, deslocado justamente por este quinto discurso, capitalista, que Lacan diz ser o discurso do Mestre "pervertido". Ele é pervertido de diferentes maneiras, como indica sua própria escrita: O que muda na transformação capitalista do DM? Aparentemente, quase nada: a inversão do sujeito e do S1. Porém, na realidade, o mais grave é a supressão dos vetores entre o sujeito e o saber: o capitalismo priva o sujeito do seu saber, ele não tem mais o saber necessário para inscrever-se no laço social que depende estritamente da possibilidade de escrever o discurso. Como cada discurso é marcado por uma disjunção que determina sua impossibilidade no denominador, a impossibilidade desaparece entre o mais-de-gozar e a verdade. Enfim, o desaparecimento dos vetores faz com que o discurso capitalista gire de um lugar ao outro segundo o modelo do Oito: é o oito maiúsculo e, se puder expressar-me assim, esse giro de carrossel, esse passe de mágica a partir do DM conduz-nos ao discurso do "meter",(1) como diz Lacan, e a inúmeras expressões equívocas que o verbo permite: meter no armário, meter no lixo, no desemprego, na miséria, no desuso etc., ou ainda mais trivial: evidentemente o indivíduo, pois não há mais sujeito dividido, ele se faz foder(2)... e não Mestre, eis a consequência.

Ainda nessa mesma Conferência(3), Lacan qualifica o discurso capitalista de astucioso: "só uma pequena inversão entre S1 e S, o sujeito, foi suficiente para que isso andasse como sobre rodinhas, impossível andar melhor, mas justamente isso anda depressa demais, isso se consome tão bem que isso se consuma" (Lacan, 1973/1978, p.77) : o consumismo resume muito bem esta conjunção do consumo e do consumir. Consequência menos divertida: de um lado, o sujeito desapossado do saber; do outro, todos os saberes 
reunidos em um mercado único. Isso tem como efeito que o gozo se ordena e ordena; ele é buscado e perverso. Em 1968, ansiava-se pelo gozo sem barreiras, mas era um gozo comunitário; neste caso, porém, é "eu gozo como quero, de quem quero e quando quero" com um toque sadeano, o que não promove nenhum laço social, e sim um comunitarismo que se dirige ao "tanto faz" (como se diz de um carro que tanto anda a gás quanto a gasolina).

Existe uma doxa capitalista: o mercado dita a regra, de conduta, de vida, de saúde, máquina louca que se apoia na foraclusão do sujeito que a ciência produziu. Se há um hiperconsumo nos países capitalistas, ele abrange tanto a alimentação quanto os objetos da tecnologia de ponta. O problema é a aliança indefectível entre a ciência e o mercado global. De certo modo, o capitalismo apaga o político, se entendemos por político um "way of life" que inclui o laço social. Exatamente o contrário, a regra no capitalismo é a destruição do laço social (veja-se a solidão das megalópoles ou grandes metrópoles).

\section{O tratamento do humano}

Estamos no estágio do humano conectado e o mercado inventou um Outro eletrônico, um outro virtual que faz as vezes do laço social. Entretanto, será que não há mais Outro do sujeito? Não podemos sustentar essa tese, pois o Outro é homme-ni-present.(4) O Outro é supereu e o sujeito reclama uma liberdade falsificada, bem distante de uma liberdade para todos. Vocês podem fazer tudo,

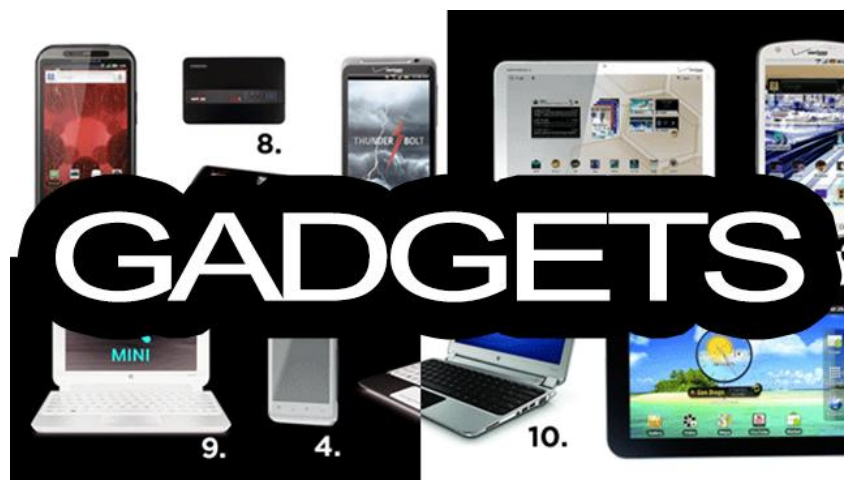
menos o que o mercado proíbe, ou seja, ter a liberdade de dizer que vocês não são livres.

É a este Outro superegoico que se faz apelo para que sejam tamponadas a angústia e a divisão. Exit para o sujeito dividido, já que ele está permanentemente conectado; exit para a angústia. O Outro vai dizer-lhe como fazer para evitá-la. Apela-se então ao supereu, à tirania, para responder por meio de um acordo com as injunções do mercado. Apple diz enfaticamente que as pessoas estão paumés(5), perdidas, pendidas (pommés) e que fazem apelo (appel)(6). $\mathrm{O}$ mundo do capitalismo simplificado foraclui o sujeito (a ciência faz o mesmo) para meter no lugar massas uniformes que agem no sentido preconizado pelo mercado (férias com tudo incluído nas cidades de férias). O que é impressionante é a coalizão, a colusão entre o político e os interesses do mercado, com a benção da ciência que produz instrumentos tecnológicos de embrutecimento das massas.

O que é que a ciência está buscando, em particular a biologia, que experimenta um grande impulso? Ela procura prolongar a vida, tripudia o ser vivo até o seu limite, transumanismo depois da clonagem. Para prolongar a vida é preciso intervir sobre o corpo, com a ajuda de todas as técnicas de transformação: esporte, alimentação, cirurgia, moda. Resultado: é a liberdade por meio das obrigações. Na psicanálise, o sujeito situa-se por uma falta em ser, o que o discurso dominante rejeita. O bem-estar não só é possível, como é uma meta a ser atingida. É preciso estar bem. Se você não está bem, você é infeliz e isso é culpa sua (quanta culpa temos!). É preciso aprender a dominar as emoções, controlar os afetos e obedecer à higiene de vida tal como recomendada: não comer, não fumar, nem beber ou ter conflitos, senão você é has-been, reacionário, você não entendeu que não há alternativa, nem individual, nem coletiva.

\section{O lugar da análise}


Não se pode mais duvidar que o capitalismo tenha efeitos sobre a clínica. Nem é preciso que a gente se refira à explosão da depressão, os transtornos ditos bipolares e de adição às drogas, ao álcool, aos jogos eletrônicos, à internet, ao sexo ou aos transtornos alimentares.

Podemos deduzir que esses sujeitos já não são os neuróticos clássicos de Freud. Podemos constatar a falência do desejo e o excesso do gozo, podemos constatar as falhas do simbólico: o pai foi questionado e seu declínio foi apontado, a questão mulher foi colocada e a família se estilhaçou, o recalque não preocupa mais os sujeitos, as formações do inconsciente não mais chamam tanto a atenção. Tudo isso advém de uma constatação estéril. O que não é estéril é que, nesse meio tempo, a prática da psicanálise não apenas permanece, ela inclusive se intensifica.

Como tratar nos dias de hoje os casos "especiais" que não entram diretamente em nossas categorias estruturais mais comuns? Como fazê-los entrar em análise, no discurso analítico? Freud e seu Unbehagen in der Kultur(7), Lacan em seu Seminário O avesso da psicanálise (1992), Hèléne Cixous em sua interrogação sobre o humano, Patrick Laupin (2007) e muitos outros abordaram o problema sob o ângulo civilizatório, ético e humano. Eles dão aos psicanalistas os meios- mas é preciso que o sujeito os demande - de preservar a possibilidade de se inscrever no laço social a partir da singularidade, de seu modo singular de responder a esse real de que "Não há relação sexual". Em sua conferência A terceira(8), Lacan interroga o futuro da psicanálise, conectando-o a uma questão sobre o sintoma: "Será que a psicanálise é um sintoma?" Ele acrescenta: "Chamo sintoma o que vem do Real". Como tratar esse sintoma? O sentido do sintoma não é aquele com o qual nós o alimentamos para que ele prolifere, "o sentido do sintoma é o real, na medida em que ele se põe em cruz". Portanto: "o sentido do sintoma depende do futuro do real"; logo, do sucesso da psicanálise. "O que lhe pedimos é que ela nos desembarace tanto do Real quanto do sintoma". Creio que vocês concordarão comigo em dizer que, no momento atual, não estamos caminhando nessa direção.

O que Lacan opõe à pergunta da análise como sintoma? Uma resposta sem equívoco, perfeitamente adaptada ao que vivemos atualmente: "Há apenas um sintoma social: cada indivíduo é realmente um proletário, quer dizer, não tem nenhum discurso para fazer laço social, em outras palavras, semblante". Mas então, como fazer laço social? Lacan recorre ao discurso analítico, um discurso em que o lugar do semblante é ocupado pelo analista que é suposto saber de onde procede quando ocupa este lugar. A eficácia da análise tem a ver com o fato de que ela instaura um laço a dois e, assim, faz suplência à falta de relação sexual. Esse laço autoriza a pensar em outra forma de distribuir os gozos e de localizar o sintoma: gozo fálico, gozo do corpo que é gozo da vida. O sintoma é a irrupção desta anomalia em que consiste o gozo fálico já que ele responde à não-relação sexual. A aposta da psicanálise situase no lugar em que o sintoma pode recuar, logo a interpretação equívoca é necessária, porque ela atinge o que sustenta o simbólico, ou seja, lalíngua. É o "saber inscrito de lalíngua que constitui, falando com propriedade, a elaboração possível do inconsciente que vence o sintoma".

Falei do gozo fálico, do gozo do sentido. É preciso acrescentar o gozo do Outro, que está situado na interseção do Real e do Imaginário no nó borromeano, está fora do sentido, fora da linguagem, fora do simbólico. Ora, é a partir deste J(A) que se abre o acesso ao real, na dimensão da letra. A letra não é o sentido. É preciso que o sentido que procede do simbólico e da morte se dispa para atingir a dimensão da letra, única a conferir uma identidade. A questão identitária invade a clínica atual, creio que podemos responder a partir da última parte do ensino de Lacan: se a psicanálise não está ultrapassada nem esvaziada sob o ponto de vista da clínica atual, isso tem a ver, para Lacan, com seu fundamento, o qual, sem dúvida, combina ainda melhor com a clínica atual. Os analisantes fantasiam menos, o que é 
bem compreensível, já que estão excluídos do discurso. Em contrapartida, eles gozam bem mais, são mais servos do seu próprio sintoma. Ora, nos anos 1975, ao fim da sua reflexão sobre o gozo sexual que advém do coito, Lacan atém-se precisamente ao gozo do sintoma, para examinar o ponto em que o gozo feminino se duplica em seu percurso, e o "não todo fálico" deu a medida do fracasso da relação sexual.

O essencial do avanço de Lacan repousa sobre o lugar do sintoma e o real que está em jogo nele. Lacan chegou então a produzir de um lado o fala-a-ser que vem substituir o sujeito, de outro, o sinthoma como modalidade de gozo próprio a um sujeito, singular. Nesse ponto, é preciso adaptar-se ao deslocamento que isso engendra para a ética da análise, ética do desejo, dizemos nós: escolha do sujeito.

Os novos fenômenos produzidos pela crise do capitalismo científico provocaram uma inflexão da ética no sentido da dimensão da responsabilidade. Digo para os analistas, tal responsabilidade é sexual, leva em consideração a não-relação sexual que é exatamente o real da psicanálise enquanto impossível e que nenhum gadget pode erradicar. Dito de outro modo, a ética complementa-se com a responsabilidade, complementa-se com o que faz singularidade, ou seja, a relação que o sujeito mantém com o sinthoma, quer dizer, com o gozo residual do sintoma. Ele é alcançado na análise no nível do dizer, que é uma função existencial.

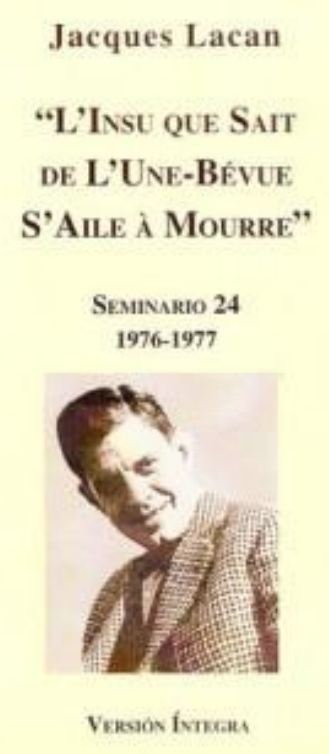

um puro produto do mercado.

A psicanálise procede hoje, portanto, de uma certa urgência: restaurar, criar o laço social a partir das respostas possíveis, alternativas para o capitalismo tingido de ciência e de finança, a partir da crítica da norma, da exclusão e do solipsismo.

O livro A angústia do goleiro no momento do pênalti (1970), do escritor alemão Peter Handke, apresenta a angústia da solidão e da responsabilidade, não para remoer o traumatismo brasileiro da última Copa do Mundo, e sim para dizer que, se o psicanalista, em sua análise, deve ter experimentado a solidão e a falta radical diante da inexistência do Outro e o exílio da relação sexual, resta, porém, à medida que se inscreve no discurso analítico, a garantia da possibilidade de laço social para oferecer segurança ao conceito de angústia. Trata-se de um laço social que considera o impossível - contrariamente ao que o discurso dominante demanda, reclama, institui, impõe, ou seja, o "dizer-tudo-fazer-tudo-ter-tudo": não dizer tudo, não ter tudo, não-tudo fazer, mas, ao contrário, saber que há divisão, perda e falta.

Não posso desenvolver esse ponto, mas - e é um dos campos cruciais no plano social - o laço social que a psicanálise lacaniana propõe é contrário à exclusão das mulheres e a 
considerá-las de forma diferente ao modelo da paridade igualitária, sobre o modo da diferença.

\section{Conclusão... e solução}

Deixei de lado muitas coisas que entram no campo dos efeitos do Discurso capitalista (lista não exaustiva): a) o corpo e suas transformações: a cirurgia estética, a imortalidade e o transumanismo, as dietas alimentares; b) seu corolário, a saúde: bioética e biogenética; c) as mídias, a publicidade da imprensa, a televisão e seus maravilhosos canais de permanente desinformação; e d) as redes sociais e a internet: a ilusão do laço social que depende do discurso, depende do que se articula entre os seres falantes.

Finalmente, gostaria de transmitir uma mensagem: “A psicanálise não está morta!” Ela tem muitos dias pela frente enquanto o mercado não apreende que a multiplicidade de gadgets postos diariamente à disposição do sujeito não o satisfaz (ou enquanto fornece falsas respostas). Não basta dizer "Trabalhem para possuir estes gadgets" que, na realidade, é "Trabalhem cada dia mais e, quanto ao desejo, um dia vocês o recuperam"; a própria posse dos gadgets representa, para o sujeito, a oportunidade que tem de aperceber-se de que esses mais-de-gozar são falsos mais-de-gozar. Há chance para os psicanalistas que, depois do fracasso das técnicas cognitivo-comportamentais e das outras técnicas de bem-estar, são procurados pelos sujeitos para tratar seu sentimento de vazio, sua depressão e ausência de projeto, seu tédio e sua morosidade, o sentimento de nulidade e de impotência em sua busca da felicidade, e, sobretudo, os problemas da vida em comum com seu parceiro, homo ou hétero.

Sabemos que o discurso capitalista "ignora as coisas do amor". Ora, é frequentemente pela angústia gerada pelas coisas do amor que os sujeitos vêm fazer uma demanda de análise. A análise então lhes propõe - no fim de um caminho por vezes longo - substituir a ideologia do bem-estar, que enriquece sempre a mesma minoria de pessoas, pelo acesso a uma ética do Bem-Dizer, uma ética que implica o dizer, mais adequada a sua condição não apenas de ser humano, mas de fala-a-ser. Ela lhes oferece a possibilidade, a alternativa de inscrever-se em um laço social, mas qual? Os excluídos, os solitários, os celibatários não desaparecerão rapidamente. Isso não impede que a psicanálise produza, para além do laço a dois do par analisante-analista, o que Lacan nomeou de os "esparsos disparatados" (Lacan, 2003/1976, p. 569) e que a questão se torne então: como manter juntos esses esparsos disparatados?

E há o acaso suplementar que é a verdadeira chance da análise: a dita-mansão do Dizer. O dizer é o próprio signo do sujeito, ele é a possibilidade do fato "Que se diga". O fato é que cada vez mais pessoas procuram análise, pois a angústia ou os sintomas lhes assinalam que eles não podem manter-se totalmente no espaço científico-capitalista do mercado e que é patente o fracasso do "care"(9).

A alternativa, as alternativas sociais emergem da própria crise. Incurável, a crise se tornou crônica, criando uma dimensão insuportável para muitos indivíduos. O interessante na crise é a saída, o desembocar da crise. Ela não se faz sem invenção e, como faz notar o psicanalista Slavoj Zizek em sua obra, temos o direito de pensar, de refletir em novas alternativas para sair desse sistema. Para isso, é preciso, sobretudo, inventar novas formas de viver juntos, não apenas desejar novas formas, ansiar por elas, mas inventá-las. É preciso dar um passo a mais. É certo que Podemos, mas também Queremos: é preciso querer o que se deseja.

\section{Notas}


(1) (N.T.) No original: discours du mettre, que faz homofonia com discours du maître, mas também com discours du m'être, outra expressão de Lacan (1972-1973) que se encontra em O Seminário, livro 20: mais, ainda. Outra tradução possível teria sido "discurso do pôr", porém "meter" é mais próximo de "mestre", tanto do ponto de vista gráfico, quanto sonoro.

(2) Em gíria francesa, "se faire mettre" equivale a "se faire foutre", ou seja, fazer-se foder.

(3) Conferência pronunciada no Museu da ciência e da técnica de Milão, em 3 de fevereiro de 1973.

(4) (N.T.) Em português, literalmente, "homem-nem-presente"; em francês, homofônico a omniprésent, onipresente.

(5) (N.T.) O autor joga com a homofonia entre paumé, perdido, e pommé, feito maçã, pomme.

(6) (N.T.) Da palavra francesa appel, apelo, à palavra inglesa, apple, desloca-se apenas uma letra.

(7) O mal-estar na cultura, 1929.

(8) (N.T.) Conferência pronunciada em Roma, em $1^{\circ}$ de novembro de 1974. (Não há versão estabelecida. Em português, encontra-se nos Cadernos Lacan, volume 2, publicação não comercial, circulação interna da Associação psicanalítica de Porto Alegre). Faz série com "Função e campo da fala e da linguagem", também chamada de Primeiro discurso de Roma, e "A psicanálise, razão de um fracasso", segundo discurso de Roma.

(9) (N.T.) Possível referência às diferentes práticas de "cuidado", tipo home care, e aos "cuidadores".

\section{Referências}

Freud, S. (1974). O Mal-estar na civilização. Em Edição Standart Brasileira das Obras Psicológicas Completas de Sigmund Freud. Rio de Janeiro: Imago. v. XXI. (Original publicado em 1929-1930).

Freud, S. (1976). Totem e Tabu. Em Edição Standard Brasileira das Obras Psicológicas Completas de Sigmund Freud. Rio de Janeiro: Imago. v. XIII (Original publicado em 19121913).

Handke, P. (1970). L'angoisse du gardien de buta au moment du pénalty. Paris: Gallimard.

Lacan, J. (1973). Conferência de Jacques Lacan em Milão. Em Lacan in Italia 1953-1978. Milão: La Salamandra, 1978, pp. 58-77.

Lacan, J. (1974) A Terceira. Conferência de Jacques Lacan em Roma, em $1^{\text {o }}$ de novembro de 1974. Em Cadernos Lacan, volume 2. Publicação não comercial. Circulação interna da Associação Psicanalítica de Porto Alegre, março de 2002, pp.39-71.

Lacan, J. (1992). O Seminário, livro 17: o avesso da psicanálise. Rio de Janeiro: Jorge Zahar. (Original publicado em 1991)

Lacan, J. (1976-77). Le Séminaire, livre XXIV: l'insu que sait de l'une-bévue s'aile à mourre. Paris: AFI. Mimeo

Lacan, J. (2003). Proposição de 9 de outubro de 1967 sobre o psicanalista da Escola Primeira versão. Em Outros escritos. Rio de Janeiro: Jorge Zahar. (Original publicado em 1967).

Laupin, P. (2007). L'Homme imprononçable. France: La rumeur libre éditions.

Citação/Citation: Nguyên, A. (2016) A irrupção do político: resposta da psicanálise e o laço social. Trivium: Estudos Interdisciplinares (Ano VIII, v. 2), p. 208-214. 
Recebido em: 08/12/2015

Aprovado em: 20/02/2016 